\title{
Effect of Ti on phase stability and strengthening mechanisms of a nanocrystalline CoCrFeMnNi high-entropy alloy
}

\author{
Hamed Shahmir ${ }^{\mathrm{a},{ }^{,},}$Mahmoud Nili-Ahmadabadi ${ }^{\mathrm{a}, \mathrm{b}}$, Ahad Shafiee ${ }^{\mathrm{a}}$, Mariusz Andrzejczuk ${ }^{\mathrm{c}}$, \\ Małgorzata Lewandowska ${ }^{\mathrm{c}}$, Terence G. Langdon ${ }^{\mathrm{d}}$ \\ ${ }^{a}$ School of Metallurgy and Materials, College of Engineering, \\ University of Tehran, Tehran, Iran \\ ${ }^{b}$ Center of Excellence for High Performance Materials, School of Metallurgy and Materials, \\ College of Engineering, University of Tehran, Tehran, Iran \\ ${ }^{c}$ Faculty of Materials Science and Engineering, Warsaw University of Technology, \\ Woloska 141, 02-507 Warsaw, Poland \\ ${ }^{d}$ Materials Research Group, Faculty of Engineering and the Environment, \\ University of Southampton, Southampton SO17 1BJ, UK
}

\begin{abstract}
A CoCrFeNiMnTi $i_{0.1}$ high-entropy alloy (HEA) was processed by high-pressure torsion (HPT) followed by post-deformation annealing (PDA) at 200-900 ${ }^{\circ} \mathrm{C}$. Microstructural evaluations revealed that the initial and HPT-processed microstructures consisted of a single $f c c$ phase and there was no evidence for decomposition during severe plastic deformation. However, PDA at temperatures below $900{ }^{\circ} \mathrm{C}$ promoted the formation of a multi-phase microstructure containing new precipitates and significant grain coarsening occurred after PDA at $>800{ }^{\circ} \mathrm{C}$ due to a dissolution of the precipitates. PDA at $800{ }^{\circ} \mathrm{C}$ for $60 \mathrm{~min}$ led to very good mechanical properties with an ultimate tensile strength (UTS) and elongation to failure of $>1000 \mathrm{MPa}$ and $\sim 40 \%$, respectively. The results demonstrate that the minor addition of $\mathrm{Ti}$ to the CoCrFeNiMn alloy has no direct effect on the strengthening mechanisms but nevertheless this addition significantly increases the thermal stability of the precipitates and these precipitates are effective in minimizing grain coarsening. Therefore, the Ti addition plays an important role in strengthening the HEA.
\end{abstract}

Keywords: CoCrFeNiMnTi; High-entropy alloy; High-pressure torsion; Post-deformation annealing; Severe plastic deformation.

*Corresponding author. Tel.: +982182804163

E-mail address: H.Shahmir@ut.ac.ir 


\section{Introduction}

The CoCrFeNiMn high-entropy alloy (HEA) is an equiatomic alloy with a single-phase structure which is one of the most widely and best studied HEAs. Even though the five elements in this quinary system possess different crystal structures, the alloy crystallizes as a single-phase $f_{c c}$ solid solution. In fact, a potential combination of high solid solution strengthening and good ductility may be achieved in this alloy because the solid solution phase possesses a simple crystal structure such as an $f c c$ lattice with the associated large number of active slip systems [1-3]. The CoCrFeNiMn alloy generally exhibits outstanding ductility and fracture toughness properties even at liquid nitrogen temperature [4] but shows relatively low strength $(<500 \mathrm{MPa})$ in the homogenized condition [5]. In order to increase the strength of this alloy, additional strengthening methods may be introduced such as grain refinement by severe plastic deformation (SPD) processing. High-pressure torsion (HPT) is a well-established procedure for producing ultrafine and even nanostructured grains in metals and alloys [6-8] and it has been shown that processing of the CoCrFeNiMn HEA by HPT leads to significant hardening and grain refinement but also significantly reduces the ductility $[9,10]$. This behaviour of nanostructured alloys processed by HPT is due to their low rate of strain hardening and low strain rate sensitivity [11,12]. These results demonstrate, therefore, that it is important to increase the strength of this alloy without significantly sacrificing the ductility.

In practice, experiments show that post-deformation annealing (PDA) of nanocrystalline materials is often capable of producing a combination of high strength and good ductility [1013]. For example, it was reported that a short-term PDA of the CoCrFeNiMn HEA for 10 min at $800{ }^{\circ} \mathrm{C}$ leads to a combination of high strength and good ductility including an ultimate tensile strength (UTS) of $\sim 830 \mathrm{MPa}$ and an elongation to failure of $\sim 65 \%$ due to a microstructure containing very fine grains $(<4 \mu \mathrm{m})$ with a low volume fraction of dispersed precipitates [10]. Therefore, in order to further improve the strength without losing the plastic stability, it is necessary to enhance the solid solution or precipitation hardening which therefore 
necessitates a modification of the chemical composition of the alloy.

It is well known that, in addition to the principal elements, HEAs may also contain minor elements with each concentration level below 5 at.\% [14]. Accordingly, the present research was initiated to provide detailed information on the effect of adding a minor amount of $\mathrm{Ti}$ to the CoCrFeNiMn HEA and then processing the alloy by HPT through different numbers of revolutions followed by PDA. Attention was directed specifically to examining the effect of the Ti addition on the phase stability and strengthening mechanisms of the HPT-processed CoCrFeNiMn HEA after PDA. A Ti addition was selected specifically because it was believed that the larger atomic radius of $\mathrm{Ti}(\sim 176 \mathrm{pm})$ by comparison with the average atomic radius for the other elements $(\sim 155 \mathrm{pm})$, combined with the propensity of this atom to easily form bonding with other elements, may significantly affect the physical and mechanical behavior of the CoCrFeNiMn HEA.

\section{Experimental material and procedures}

The experiments were conducted on an HEA with a nominal composition of CoCrFeNiMnTi ${ }_{0.1}\left(\mathrm{Co}_{19.6} \mathrm{Cr}_{19.6} \mathrm{Fe}_{19.6} \mathrm{Ni}_{19.6} \mathrm{Mn}_{19.6} \mathrm{Ti}_{2}\right.$ in at.\%). The HEA was prepared using a non-consumable vacuum arc melting technique in a water-cooled copper crucible. Pure titanium was also melted and used as a getter in the chamber. After four remeltings to achieve reasonable homogenization, the ingot was hot forged and then homogenized at $1000{ }^{\circ} \mathrm{C}$ for 960 min under an Ar-controlled atmosphere. Disks having diameters of $10 \mathrm{~mm}$ were prepared with electro-discharge machining to thicknesses of $\sim 1 \mathrm{~mm}$ and they were then polished mechanically to final thicknesses of $\sim 0.8 \mathrm{~mm}$. These disks were processed by HPT at room temperature under quasi-constrained conditions [15] using an applied pressure, $P$, of $6.0 \mathrm{GPa}$ and a rotation speed of $1 \mathrm{rpm}$ through totals, $N$, of $1 / 4,1,5$ and 10 revolutions. The disks subjected to HPT through 5 rotations were subsequently subjected to PDA at temperatures from 200 to $900{ }^{\circ} \mathrm{C}$ for $60 \mathrm{~min}$. 
Each HPT-processed disk was polished to a mirror-like quality and hardness measurements and X-ray diffraction (XRD) were taken on the top surfaces. The average microhardness values, Hv, were measured along randomly selected diameters on each disk using a Vickers microhardness tester with a load of $500 \mathrm{gf}$ and dwell times of $10 \mathrm{~s}$. These measurements were taken at intervals of $\sim 0.5 \mathrm{~mm}$ and at every point the local value of $\mathrm{Hv}$ was obtained from the average of four separate hardness values. In order to study the phase constituents by $\mathrm{XRD}, \mathrm{Cu}$ $\mathrm{K} \alpha$ radiation was used (wavelength $\lambda=0.154 \mathrm{~nm}$ ) at $45 \mathrm{kV}$ with a tube current of $200 \mathrm{~mA}$ in Rigaku SmartLab equipment. These measurements were performed using a scanning step of $0.01^{\circ}$ and a scanning speed of $2^{\circ} \min ^{-1}$ over a range of $2 \theta$ from $30^{\circ}$ to $100^{\circ}$.

Optical microscopy (OM), field-emission scanning electron microscopy (FESEM) and transmission electron microscopy (TEM) were carried out to provide the microstructural characterizations. Samples from areas near the disk edges were ground through 800, 1200 and 4000 grit $\mathrm{SiC}$ papers and then polished using a $40 \mathrm{~nm}$ colloidal silica suspension for the $\mathrm{OM}$ and FESEM observations. The TEM foils were prepared before and after PDA at $600{ }^{\circ} \mathrm{C}$ for 60 min using a focused ion beam (FIB) Hitachi NB5000 FIB facility and Gentle Mill Technoorg Linda at $3 \mathrm{~mm}$ from the disk centres in the normal sections of the disks so that the normals of the images lay in the shear direction. The TEM micrographs were obtained using a JEM 1200 JEOL microscope.

For tensile testing at room temperature, two miniature tensile specimens with gauge dimensions of $1.1 \times 1.0 \times 0.6 \mathrm{~mm}^{3}$ were cut from symmetric off-centre positions near the edges of each disk using electro-discharge machining. Similar tensile samples were also prepared from the initial cast HEA without HPT. The mechanical properties were then examined in the HEA in the initial condition before HPT and after HPT processing followed by PDA at 773$1173 \mathrm{~K}$ for $60 \mathrm{~min}$. Stress-strain curves were recorded using an initial strain rate of $\sim 1.0 \times 10^{-3}$ $\mathrm{s}^{-1}$ with a Zwick universal testing machine. To achieve good reproducibility, two samples were tested for each condition. The stress-strain curves were plotted for each specimen and the 
values of the UTS were derived directly from the curves. The elongations were estimated by carefully measuring the gauge lengths before and after tensile testing using an optical microscope.

\section{Experimental results}

\subsection{Hardness and microstructural evolution during HPT}

The initial homogenized microstructure of the HEA prior to HPT is shown in Fig. 1 where this microstructure is typical of a fully-annealed sample consisting of equiaxed grains with average sizes of $\sim 200 \mu \mathrm{m}$. Some of these grains contain twins which apparently form due to the thermomechanical processing, including hot forging and annealing, conducted before the HPT processing. Close inspection shows also that many of these grains have faceted boundaries which correspond to coherent interfaces in which there is no driving force for grain growth due to any grain boundary curvature. Some particles are present in the homogenized condition as marked by arrows in Fig. 1 and it was shown using energy dispersive X-ray spectroscopy (EDS) that these particles exhibit oxygen, titanium and manganese peaks which indicate the presence of Ti-Mn oxides. Nevertheless, it is noted that the volume fraction of these particles is essentially negligible. The results of the EDS show also that the chemical composition of the HEA, $\mathrm{Co}_{19} \mathrm{Cr}_{18} \mathrm{Fe}_{21} \mathrm{Ni}_{20} \mathrm{Mn}_{20} \mathrm{Ti}_{2}$ in at.\%, is very close to the nominal composition.

Results for the Vickers microhardness measurements are shown in Fig. 2 after processing through different numbers of turns with the average values of $\mathrm{Hv}$ plotted along each disk diameter and with the lower dashed line at $\mathrm{Hv} \approx 140$ corresponding to the initial hardness in the homogenized condition before HPT. Inspection of Fig. 2 shows that, with reference to the homogenized condition, the hardness at the edge of the disk increases significantly to $\mathrm{Hv} \approx 430$ after only $1 / 4$ turn whereas the hardness in the centre increases only to $\mathrm{Hv} \approx 250$. At the edges of the disks there is almost no further increase in hardness to $\mathrm{Hv} \approx 450$ after 1,5 and 10 turns whereas in the centre the hardness values gradually increase to $\mathrm{Hv} \approx 390$ after 10 turns. These 
results confirm the evolution in hardness with increasing torsional straining and the presence of a saturation hardness at $\mathrm{Hv} \approx 460$. Nevertheless, there is a radius of $r<1 \mathrm{~mm}$ at the centre of the disk where there is lower hardness even after 10 turns. The results demonstrate also that there is no significant difference between the hardness of samples processed through 5 and 10 turns at radii larger than $\sim 1 \mathrm{~mm}$.

The XRD patterns for the initial homogenized sample (designated as $N=0$ ) and near the edges of disks after HPT through 1 and 5 turns are presented in Fig. 3. It is readily apparent that the initial and HPT-processed microstructures consist of a single $f c c$ phase. The main $f c c$ peak for the initial condition is located at $2 \theta \approx 43.38^{\circ}$ with a lattice parameter of $a \approx 3.61 \AA$ where this lattice parameter is only slightly higher than for the conventional CoCrFeNiMn HEA where $a \approx 3.60 \AA[10]$. There is no evidence for the occurrence of any phase transformation or the formation of precipitates during the HPT processing and the only significant change is a minor peak broadening due to the HPT processing. These broadenings were examined for determinations of the grain size in the HPT-processed HEA alloy using the classic WilliamsonHall method $[16,17]$ and from these calculations the grain size of the CoCrFeNiMnTi HEA after HPT processing was estimated as $\sim 40 \mathrm{~nm}$.

Figure 4 shows two different magnifications of the microstructure of the HEA after 5 turns of HPT at a position about $3 \mathrm{~mm}$ from the disk centre. These TEM images demonstrate that the processed microstructure consists of an array of equiaxed nanostructured grains having an average size of $\sim 40 \mathrm{~nm}$ and with many of the grains surrounded by diffuse or ill-defined grain boundaries. In addition, strain contrast is visible in many of the nano-scale grains which is associated with the presence of dislocations. The appearance of this microstructure is generally typical of conventional metals prepared using SPD techniques and it is consistent with the presence of a large volume of high-energy non-equilibrium boundaries [18]. The arrangement of the diffraction spots in semi-continuous circles in the selected area electron diffraction (SAED) pattern in Fig. 4(a) confirms that the microstructure contains boundaries having high 
angles of misorientation and indexing of the rings demonstrates that this is a single $f c c$ phase.

\subsection{Hardness values and microstructures after PDA}

The measured values of the microhardness for the homogenized sample and the HPTprocessed samples after annealing at temperatures of 200 to $900{ }^{\circ} \mathrm{C}$ for a period of $60 \mathrm{~min}$ are shown in Fig. 5. These results indicate that the hardness of the HPT-processed samples increases up to $\mathrm{Hv} \approx 550$ after annealing at $500{ }^{\circ} \mathrm{C}$. Furthermore, the hardness increment is clearly very significance after PDA at temperatures above $\sim 200{ }^{\circ} \mathrm{C}$. The hardness values also decrease with increasing annealing temperatures up to $900{ }^{\circ} \mathrm{C}$ and this decrease is significant at temperatures above $600{ }^{\circ} \mathrm{C}$. The hardness values of the homogenized sample after PDA are shown by the lower results in Fig. 5 and this gives a maximum hardness in the coarse-grained material of only $\mathrm{Hv} \approx 155$ after annealing at $600{ }^{\circ} \mathrm{C}$. This behavior suggests that precipitates are formed during annealing of both the unprocessed and the HPT-processed HEA. It is important to note also that the final hardness of the HPT sample after PDA at $900{ }^{\circ} \mathrm{C}$ is very close to the value for the homogenized condition so that almost all of the hardness increment has been removed. A summary of all of the microhardness results after PDA, as well as the measured values for the yield stress (YS), UTS and elongations to failure, $\delta$, are given in the upper part of Table 1 and these results may be compared with the conventional CoCrFeNiMn HEA without the Ti addition as reported earlier [10] and shown in the lower part of Table 1.

Figure 6 gives the XRD patterns of samples before and after PDA at temperatures from 500 to $900{ }^{\circ} \mathrm{C}$ and the results show clearly the microstructural evolution that occurs due to the formation of several new peaks after PDA. Thus, close inspection of Fig. 6 reveals the formation of new peaks marked with solid inverse triangles at $2 \theta \approx 44.2^{\circ}$ which correspond to the formation of a $b c c$ phase with a lattice parameter of $a \approx 2.88 \AA$. This phase is consistent with the Cr-rich phase reported earlier in the CoCrFeNiMn HEA [9,10,19,20]. In addition, in Fig. 6 there is the appearance of some additional peaks having very low intensities and marked 
with open inverse triangles after annealing at 600 to $800{ }^{\circ} \mathrm{C}$. The crystal structure of this secondary phase was identified as tetragonal with lattice parameters of $a \approx 8.8 \AA$ and $c \approx 4.5 \AA$, where this is consistent with the topologically close-packed (TCP) $\sigma$-phase which is a hard Crrich phase reported earlier in HEAs [10,21-24]. Close inspection of the XRD patterns shows also that the microstructure is again single phase after annealing at the highest temperature of $900{ }^{\circ} \mathrm{C}$. The volume fractions of precipitates, $V_{p}$, were calculated based on the XRD results and these results are shown in the fourth column in Table 1.

TEM images and an appropriate SAED pattern are shown in Fig. 7 for the sample after PDA at $600{ }^{\circ} \mathrm{C}$ for $60 \mathrm{~min}$. The microstructure in Fig. 7(a) contains equiaxed grains with an estimated mean grain size of $\sim 100 \mathrm{~nm}$. It is readily apparent that there is a pronounced change in the diffraction patterns after conducting PDA from continuous to discontinuous rings as shown in Fig. 7(b). The rings in this pattern determine the $f c c$ planes which are related to the matrix and the new sets of spots are clearly revealed after PDA at $600{ }^{\circ} \mathrm{C}$ which confirm the occurrence of precipitation with one set of these new spots corresponding to the $b c c, f c c$ and $\sigma$ phases. It was suggested that this second $f c c$-phase, which is located mainly between the $(111)_{f c c}$ and $(200)_{f c c}$ rings, is related to the $\mathrm{NiMn}(\mathrm{Cr}, \mathrm{Fe}, \mathrm{Co})$ phase which corresponds to the forming of nano-scale precipitates during annealing after SPD [9,10].

The dark field image shown in Fig. 7(c) indicates a dispersion of $b c c$ precipitates in the matrix with an average size of $\sim 100 \mathrm{~nm}$ and there is a dispersion of two sets of precipitates in the microstructure shown in Fig. 7(d). First, nano-spherical precipitates with an average size of $\sim 25 \mathrm{~nm}$ (NiMn-rich) form within the individual grains as shown by arrows and they remain small with respect to the grain size. These precipitates can be effective obstacles for dislocation motion as in dispersion hardening [25]. Second, there is also another set of precipitates formed in grain boundaries and triple junctions which may be $b c c$ and $\sigma \mathrm{Cr}$-rich phases as shown by the circles in Fig. 7(d). The formation of precipitates with similar composition was reported earlier in the grain boundaries of heavily deformed CoCrFeNiMn HEAs [10,26,27]. Chemical 
analyses were undertaken of these two regions containing the nano-precipitates and the secondary larger precipitates as illustrated in Figs 8 and 9, respectively. Thus, the composition of the region in Fig. 8 corresponds to the NiMn-rich phase which represents $f c c$ precipitates and the chemical composition of the region represented in Fig. 9 corresponds to the Cr-rich phase of $b c c$ and/or $\sigma$ phases.

The microstructures of the HEA in FESEM after PDA for 60 min at (a) 600, (b) 700 and (c) $800{ }^{\circ} \mathrm{C}$ and also in $\mathrm{OM}$ after PDA for $60 \mathrm{~min}$ at (d) $900{ }^{\circ} \mathrm{C}$ are shown in Fig. 10. These microstructures show equiaxed grains with average sizes of $\sim 100 \mathrm{~nm}$ to $\sim 14 \mu \mathrm{m}$ after PDA at 600 to $900{ }^{\circ} \mathrm{C}$ as documented in Table 1 . In addition, there is clear evidence for the existence of twins after PDA as depicted in Fig. 10(d). The FESEM micrographs of the samples annealed at 700 and $800{ }^{\circ} \mathrm{C}$ in Fig. 10 (b,c) show the existence of the precipitated phase formed at grain boundaries and triple junctions which, according to the XRD results for these annealing temperatures and TEM observations after annealing at $600{ }^{\circ} \mathrm{C}$, corresponds to precipitates of a Cr-rich phase. It is apparent that the Cr-rich phase is distributed homogenously in the microstructure in Fig. 10(b) with a grain size similar to that of the matrix in Fig. 10(a). It is also evident from Fig. 10(c) that significant grain coarsening takes place and there are no precipitates after PDA at $900{ }^{\circ} \mathrm{C}$ in Fig. 10(d) which is consistent with the XRD results in Fig. 6.

The FESEM micrographs of the etched HEA samples after PDA at (a) 700, (b) 800 and (c) $850{ }^{\circ} \mathrm{C}$ are shown in Fig. 11 where it is important to note that the etchant has a strong effect on the precipitates which leads to the separation of some precipitates from the matrix. The size and distribution of precipitates are shown in Fig. 11 with the precipitate sizes measured as $\sim 150$, $\sim 200$ and $\sim 300 \mathrm{~nm}$ after PDA at 700, 800 and $850{ }^{\circ} \mathrm{C}$, respectively. Analyses by EDS of the matrix and other precipitates are also given in Fig. 11(b) and these results indicate the formation of Cr-rich precipitates in the microstructure after PDA at temperatures below $900{ }^{\circ} \mathrm{C}$. 


\subsection{Mechanical properties}

Representative plots of engineering stress against engineering strain for the initial homogenized sample, a sample processed by HPT through 5 turns and samples processed by HPT for 5 turns followed by PDA for 60 min at 700 to $850{ }^{\circ} \mathrm{C}$ are shown in Fig. 12 using an initial strain rate of $1.0 \times 10^{-3} \mathrm{~s}^{-1}$. Inspection of these curves shows that the initial unprocessed sample exhibits the lowest flow stress but a large elongation to failure whereas HPT processing gives significant increases in strength but with corresponding decreases in the measured elongations. This trend is consistent with the classical mechanical behaviour of ultrafinegrained metals that are tested in tension at relatively low temperatures after processing using SPD techniques $[28,29]$. The results also demonstrate that the UTS after HPT is $\sim 2.25$ GPa and the elongation to failure is only $\sim 3 \%$ and this compares with a strength and elongation to failure in the initial homogenized condition of $\sim 630 \mathrm{MPa}$ and $\sim 85 \%$, respectively.

Figure 12 reveals also that PDA at $700{ }^{\circ} \mathrm{C}$ leads to a drop in strength and the elongation to failure remains very low and even lower than immediately after HPT processing. It should be noted that samples after PDA at 500 and $600{ }^{\circ} \mathrm{C}$ for $60 \mathrm{~min}$ (not shown in Fig. 12) exhibited brittle behaviour with fracture occurring before the yield point where this behaviour is attributed to the formation of precipitates in the microstructure during PDA. Annealing at 750 ${ }^{\circ} \mathrm{C}$ gives a reasonably high flow stress that is a direct consequence of the HPT processing but there is also an improvement in the elongation to failure and the elongations to failure of samples subjected to PDA at 800 and $850{ }^{\circ} \mathrm{C}$ show significant improvements in the elongations but with corresponding reductions in the UTS. Table 1 summarizes all of the mechanical data derived from the samples shown in Fig. 12. It appears from these results that PDA at a temperature of $800{ }^{\circ} \mathrm{C}$ represents the optimum condition for achieving reasonable strength coupled with good ductility with a UTS of $\sim 1060 \mathrm{MPa}$ and an elongation to failure of $\sim 40 \%$. 


\section{Discussion}

\subsection{The phase stability of the nanocrystalline HEA after PDA}

The initial and HPT-processed microstructures in this HEA consist of a single $f c c$ phase. It is well-known that the CoCrFeNiMn HEA is a precipitation-hardened alloy [19-24] and therefore the formation of precipitates after annealing at intermediate temperature is predictable in this alloy after adding a minor amount of Ti. An increase in the hardness upon annealing, combined with the XRD and microstructural evolutions evident from the experimental data, confirm the formation of new phases during PDA at temperatures from 500 to $850{ }^{\circ} \mathrm{C}$. It is important to note that precipitation is a diffusion-controlled phenomenon which will be significantly affected by the sluggish diffusion which is an inherent feature of conventional HEAs [30]. Therefore, the formation of some phases during annealing are thermodynamically probable but the kinetics of these phase transformations will control the mechanism. For example, the formation of a $\sigma$-phase was proposed earlier from thermodynamic calculations [22] but it was not detected after conventional annealing of a coarse-grained CoCrFeNiMn HEA [10]. Nevertheless, this phase was detected very recently after a long term annealing of $60 \times 10^{3} \mathrm{~min}$ at a high temperature of $700{ }^{\circ} \mathrm{C}[23,24]$ and the present research shows clearly the formation of this phase after annealing for only $60 \mathrm{~min}$ at the same temperature and even lower temperatures Apparently, the introduction of large numbers of defects and grain boundaries during the SPD processing leads to the creation of fast, or at least more rapid, diffusion pathways and these defects also act as preferential nucleation sites for the formation of precipitates. It is therefore concluded that the HPT-processed microstructure facilitates precipitation and also the kinetic formation of stable phases.

The microstructural observations confirm the formation of a $\mathrm{Cr}$-rich $b c c$ phase after PDA at $500{ }^{\circ} \mathrm{C}$ and the formation of a multi-phase nanostructured HEA after PDA at 600 to $700{ }^{\circ} \mathrm{C}$ consisting of Cr-rich $b c c$, (Ni,Mn)-rich $f c c$ and Cr-rich $\sigma$ phases. Generally, the solubility of $\mathrm{Cr}$ 
in the $f c c$ phase is quite high at high temperatures but it decreases with decreasing temperature and this leads to the formation of a Cr-rich phase at temperatures below $900{ }^{\circ} \mathrm{C}$.

The TEM images show that the Cr-rich $b c c$ is homogenously distributed in the microstructure and nano-scale precipitates of the $f c c$ and $\sigma$ phases are homogenously distributed in the primary $f c c$ phase. It appears that the grain size of the nanocrystalline HEA is almost the same as the size of the $\mathrm{Cr}$-rich $b c c$ precipitates after PDA up to $700{ }^{\circ} \mathrm{C}$. Furthermore, the size of these precipitates is smaller than the matrix grain size in PDA at temperatures higher than $\sim 700{ }^{\circ} \mathrm{C}$ so that all precipitates disappear after PDA at $900{ }^{\circ} \mathrm{C}$.

These results indicate a general coarsening of the nanocrystalline HEA after PDA at temperatures above $800{ }^{\circ} \mathrm{C}$ and this is consistent with the concomitant dissolution of the precipitates. It is well known that the HEA has a strong resistance against grain coarsening during annealing due to the high lattice distortion energy and the sluggish diffusion [30-33]. Close inspection of the hardness data shows that the hardness decreases significantly above 500 ${ }^{\circ} \mathrm{C}$ due to a dissolution of the precipitates and the activation of a recrystallization mechanism up to $900{ }^{\circ} \mathrm{C}$ so that finally, at the highest temperature, the hardness becomes essentially equal to the homogenized condition due to the intensive microstructural coarsening.

\subsection{The mechanical properties after post-deformation annealing}

Based on the very low elongations to failure of the nanocrystalline HEA after HPT processing, which are readily apparent from Fig. 12, it is reasonable to propose that PDA may be employed to improve the ductility of the nanostructured $\mathrm{CoCrFeNiMnTi} \mathrm{C}_{0.1} \mathrm{HEA}$. The results show that the alloy is very brittle due to the formation of precipitates after PDA at 500 to 700 ${ }^{\circ} \mathrm{C}$ and this is due to a combination of the nanostructure which has the characteristics of conventional HPT-processed microstructures and the formation of new phases having intermetallic characters which provide high strength.

It is reasonable to anticipate that the high energy grain boundaries in nanostructured HEA 
are preferential nucleation sites for the new phases such as the Cr-rich precipitates. Thus, the precipitation of these high strength phases at grain boundaries hinders the motion of dislocations and the emission of dislocations from the boundaries. The results documented in Fig 7 reveal the formation of a Cr-rich phase having typical dimensions that are similar to the grain size of the matrix. Nevertheless, close inspection of Fig. 7(d) reveals the existence of nano-spherical precipitates situated within the individual grains which will be very effective obstacles for dislocation motion as in the dispersion hardening of grains. This suggests that the strengthening is not explained exclusively by the formation of precipitates at the grain boundaries.

The present results suggest that PDA at temperatures of 700 and up to $850{ }^{\circ} \mathrm{C}$ maintains the strength at a reasonable level while the ductility is regained. Nevertheless, PDA at temperatures below $700{ }^{\circ} \mathrm{C}$ cause brittleness in the HEA due to precipitate formation and conversely the precipitated phases disappear at $900{ }^{\circ} \mathrm{C}$ where grain coarsening leads to a drop in strength.

It appears that the selection of an appropriate PDA temperature may produce both reasonable ductility and high strength in the nanostructured $\mathrm{CoCrFeNiMnTi} \mathrm{i}_{0.1}$ HEA due to the effect of these brittle precipitates, especially the $\sigma$ phase, on ductility in the nanostructured HEA and the consequent reduction in the effect of PDA at excessively high temperatures due to grain coarsening. The elongations to failure of samples after PDA at 750 and $800{ }^{\circ} \mathrm{C}$ show a significant improvement by comparison both with other PDA conditions and with the homogenized sample. Inspection of Table 1 reveals that PDA at a temperature of $800{ }^{\circ} \mathrm{C}$ is the optimum condition for achieving reasonable strength (>1 GPa) coupled with high ductility $(\sim 40 \%)$.

\subsection{The effect of Ti on phase stability and the mechanical properties of the CoCrFeNiMn HEA}

In order to determine the effect of the addition of a minor amount of $\mathrm{Ti}$ on the mechanical properties of the CoCrFeNiMn HEA, Table 1 also presents a summary, in the lower section, of the results available from an earlier investigation [10] for the YS, UTS and the elongations to 
failure after PDA for CoCrFeNiMn. The important conclusion from this comparison is that the mechanical properties are significantly enhanced in the CoCrFeNiMn HEA through the addition of only a very small amount (2 at.\%) of Ti.

Table 1 also includes the experimental data for the grain sizes, $d$, and the volume fractions of precipitates, $V_{p}$, in the CoCrFeNiMn and $\mathrm{CoCrFeNiMnTi}{ }_{0.1}$ HEAs where the values of these quantities were estimated from combinations of TEM and FESEM observations and XRD data. Inspection of Table 1 shows there are smaller grain sizes and higher volume fractions of precipitates in the CoCrFeNiMnTi $i_{0.1}$ HEA and both of these changes effectively enhance the mechanical properties. A comparison between precipitate stability in the two HEAs shows that the precipitates are more stable in the alloy containing a small amount of $\mathrm{Ti}$ because the precipitates then effectively lock the grain boundaries and prevent coarsening. It is readily observed that there is significant grain coarsening after dissolution of these precipitates. For example, the precipitates are almost fully removed in the CoCrFeNiMn HEA after PDA at 800 ${ }^{\circ} \mathrm{C}[10]$ but in the $\mathrm{CoCrFeNiMnTi}{ }_{0.1}$ HEA this removal is most readily observed after annealing at $900{ }^{\circ} \mathrm{C}$. The greater phase stability of the $\mathrm{CoCrFeNiMnTi} i_{0.1}$ is due to the decrease in the diffusion rate as a result of the solid solution effect of the Ti atoms. It was shown earlier that larger numbers of compositional elements produce increased potential energy fluctuations between the atomic lattice sites and this leads to an increase in the diffusive activation energy and thereby produces more sluggish diffusion [30]. It is important to note also that the atomic radius of $\mathrm{Ti}(176 \mathrm{pm})$ is significantly larger than the average atomic radius for the other elements $(\sim 155 \mathrm{pm})$ and this will also affect the diffusion rate in the Ti-doped HEA.

The present results show, therefore, that adding only a minor amount of $\mathrm{Ti}$ ( 2 at.\%) besides the principal elements leads to the retention of a single phase HEA at room temperature but increases the thermal stability of the multiphase after PDA and significantly improves the mechanical behaviour of the CoCrFeNiMn HEA. 


\subsection{An evaluation of the nature of the strengthening mechanisms}

An estimate of the theoretical strength according to a structure-based strength model can be used to provide important information on the nature of the strengthening mechanisms. By assuming that the yield stress, $\sigma_{0.2}$, is a simple summation of the strengthening contributions from individual factors that are acting as obstacles for dislocation slip, the following equation provides a correlation between the microstructure and yield stress for the $\mathrm{CoCrFeNiMnTi} i_{0.1}$ HEA after processing by HPT and PDA:

$\sigma_{0.2}=\sigma_{0}+\sigma_{\mathrm{S}(\mathrm{Ti})}+\sigma_{g b}+\sigma_{\rho}+\sigma_{P}$

where $\sigma_{0}$ is the lattice friction strength assumed as $\sim 165 \mathrm{MPa}[34]$ and $\sigma_{\mathrm{S}(\mathrm{Ti})}, \sigma_{g b}, \sigma_{\rho}$ and $\sigma_{P}$ are the contributions from the solid solution strengthening effect of $\mathrm{Ti}$ as an additive to the CoCrFeNiMn HEA, grain boundary strengthening, dislocation strengthening and precipitation strengthening, respectively.

A standard model for substitutional solid solution strengthening, based on dislocation-solute elastic interactions, may be applied directly to evaluate the role of solution strengthening caused by Ti using the following relationship [35]:

$\Delta \sigma_{\mathrm{S}(\mathrm{Ti})}=\mathrm{M} \frac{G c^{2} \varepsilon_{S}^{3 / 2}}{700}$

where $G$ is the shear modulus for $\mathrm{Ti}(\sim 42 \mathrm{GPa}), c$ is the total molar ratio of $\mathrm{Ti}$ in the simple $f c c$ matrix (2 at. \%) and $M=3.06$ is the Taylor factor. The interaction parameter, $\varepsilon_{s}$, is approximately equal to $\varepsilon_{a}=(1 / a)(\Delta a / \Delta c)$, where $a$ is the lattice constant of the CoCrFeNiMn alloy matrix. The parameter $\varepsilon_{a}$ is readily obtained from the refined XRD patterns where the lattice parameters are 0.360 and $0.361 \mathrm{~nm}$ for the quinary and Ti-added HEA, respectively. Accordingly, the strength enhancement caused by solid solution hardening in the HEA with the Ti addition is estimated as $\sim 12 \mathrm{MPa}$.

The grain boundary strengthening, $\sigma_{g b}$, is described by the classic Hall-Petch relationship $[36,37]$ and it is well known that the introduction of a high volume fraction of grain boundaries will impede dislocation motion due to the grain refinement and thereby increase the overall 
strength so that

$\sigma_{g b}=k_{y} d^{-1 / 2}$

where $k y$ is the strengthening coefficient. The strengthening coefficient for the CoCrFeNiMn alloy is equal to $226 \mathrm{MPa} . \mu \mathrm{m}^{1 / 2}[31]$ and the grain sizes before and after HPT processing and after PDA at different temperatures are documented in Table 1.

The dislocation strengthening, $\sigma_{\rho}$, is described by the Bailey-Hirsch relationship through the equation [38]

$\sigma_{\rho}=M \alpha G \mathrm{~b} \rho^{1 / 2}$

where $\alpha$ is a constant $(\sim 0.2$ [39]), $G$ is the shear modulus for the CoCrFeNiMn HEA ( $~ 81 \mathrm{GPa}$ [40]), $\mathrm{b}$ is the Burgers vector $(0.255 \mathrm{~nm}[40])$ and $\rho$ is the total dislocation density which may be estimated from the XRD results in Fig. 6 using the classic Williamson-Hall method and the following simple relationship [16]:

$\rho=\frac{2 \sqrt{3} \varepsilon}{\mathrm{b} d}$

where $\varepsilon$ is the microstrain obtained from the XRD results. Taking $b=0.255 \mathrm{~nm}$, the HPTprocessed sample gives an estimated grain size of $d \approx 40 \mathrm{~nm}$, a microstrain of $\sim 0.0095$ and a dislocation density of $\rho \approx 3 \times 10^{11} \mathrm{~cm}^{-2}$. The grain size and microstrain for the sample after PDA at $600{ }^{\circ} \mathrm{C}$ are $\sim 120 \mathrm{~nm}$ and $\sim 0.0015$, respectively, and the associated dislocation density is $\sim 1.7 \times 10^{10} \mathrm{~cm}^{-2}$

These results suggest that annealing at temperatures below $700{ }^{\circ} \mathrm{C}$ will be insufficient to annihilate the large numbers of dislocations created during HPT processing and significant grain coarsening will occur in PDA at temperatures above $700{ }^{\circ} \mathrm{C}$ leading to an annihilation of the vast majority of dislocations. Therefore, assuming that $\sim 70 \%$ and $\sim 90 \%$ of the total dislocation density is annihilated during PDA at 700 and $800{ }^{\circ} \mathrm{C}$, respectively, this leads to dislocation densities of $\sim 5.1 \times 10^{9} \mathrm{~cm}^{-2}$ and $\sim 1.7 \times 10^{9} \mathrm{~cm}^{-2}$ for samples annealed at 700 and $800{ }^{\circ} \mathrm{C}$, respectively. By comparison, fully-annealed metals have dislocation densities of the order of $\sim 1.0 \times 10^{8} \mathrm{~cm}^{-2}$ and this value may be reasonably assumed for the annealed sample at 
$900{ }^{\circ} \mathrm{C}$ where the hardness of the single phase material is very close to the homogenized sample.

Precipitation strengthening is readily evident from the microhardness measurements and tensile tests due to the formation of multi-phase precipitates during the PDA. In practice, the HPT-processed sample is initially precipitate-free and makes no contribution to any precipitation strengthening. Two sets of precipitate radii were determined from the TEM and FESEM images in Figs 7-9 where $r \approx 25 \mathrm{~nm}$ (NiMn-rich $f c c$ ) and $r \approx 100 \mathrm{~nm}$ (Cr-rich phase) after PDA after $600{ }^{\circ} \mathrm{C}$. These first and second sets of precipitates were dispersed homogeneously in the grains of the matrix and at the grain boundaries, respectively, and they can improve the material strength by the Orowan mechanism and by the rule of mixtures where these processes must be examined separately.

The Orowan mechanism is generally invoked to explain precipitation strengthening by hard precipitates using a dislocation by-pass mechanism where this mechanism occurs when the radius of the particles exceeds a critical value or is incoherent within the matrix. Thus, precipitation strengthening by the first set of precipitates may be described by this mechanism using the equation [41]:

$\sigma_{P 1}=(0.8 M G \mathrm{~b}) / \lambda$

where $\lambda$ is the average inter-precipitate spacing. The TEM image in Fig. 7(c) shows that $\lambda \approx 40$ $\mathrm{nm}$ for the sample annealed at $600{ }^{\circ} \mathrm{C}$ but the image suggests that the value of $\lambda$ is dependent on the grain size with $\lambda \approx d / 4$. Therefore, it is assumed that the appropriate values are of the order of $\sim 100$ and $\sim 300 \mathrm{~nm}$ based on the measured grain sizes shown in Table 1 for the samples after PDA at 700 and $800{ }^{\circ} \mathrm{C}$, respectively. In support of this approach, it is important to note from the XRD results in Fig. 6 that these phases are stable up to $800{ }^{\circ} \mathrm{C}$.

The second set of precipitates was distributed among grains having similar sizes and accordingly this may be described using the rule of mixtures. Thus, eq. (1) may be modified to give 
$\sigma_{0.2}=f_{1}\left(\sigma_{0}+\sigma_{\mathrm{S}(\mathrm{Ti})}+\sigma_{\mathrm{gb}}+\sigma_{\rho}+\sigma_{P 1}\right)+f_{2} \sigma_{P 2}$

where $f_{1}$ and $f_{2}$ are the volume fractions of the matrix and the second set of precipitates, respectively, and $\sigma_{P 2}$ is the strength of the precipitates. The volume fractions of precipitates were measured as $\sim 18, \sim 15$ and $\sim 8 \%$ after PDA at 600,700 and $800{ }^{\circ} \mathrm{C}$, respectively, as recorded in Table 1. The mean hardness of intermetallic phases with non-simple structures is $\mathrm{Hv} \approx 9800 \mathrm{MPa}[14]$ so that $\sigma_{P 2} \approx \mathrm{Hv} / 3 \approx 3200 \mathrm{MPa}$. The calculated strengths obtained using eq. (7) are summarized in the penultimate column in Table 2 and it is apparent that these calculated values are in good agreement with the experimental values shown in the last column of Table 2 .

In summary, an interpretation of the results indicates that grain boundary strengthening is the most important strengthening mechanism for HPT-processed sample and the precipitation strengthening arising from the precipitates present in the samples after PDA may be explained directly through a combination of the Orowan mechanism and the rule of mixtures. The results demonstrate that a minor addition of $\mathrm{Ti}$ to the CoCrFeNiMn HEA has no direct effect on the strengthening mechanism but nevertheless this element significantly increases the thermal stability of the precipitates and thus plays an important role in the strengthening mechanism.

\section{Summery and conclusions}

1. A single-phase $\mathrm{CoCrFeNiMnTi} \mathrm{i}_{0.1}$ high-entropy alloy was processed by HPT under 6.0 GPa pressure up to 10 turns at room temperature. Following processing, the average grain size was reduced to $\sim 40 \mathrm{~nm}$ and this was accompanied by an exceptional increase in the hardness and UTS.

2. The hardness of the HEA further increased after post-deformation annealing at temperatures up to $500{ }^{\circ} \mathrm{C}$ due to the formation of new phases including Cr-rich $b c c$, NiMnrich $f c c$ and Cr-rich $\sigma$ precipitates. The hardness decreased after annealing at higher temperatures up to $900{ }^{\circ} \mathrm{C}$ due to precipitate dissolution and grain coarsening. 
3. The formation of precipitates in the nanostructured HEA after PDA at 500 to $700{ }^{\circ} \mathrm{C}$ showed that PDA at temperatures above $700{ }^{\circ} \mathrm{C}$ was the optimum condition for maintaining strength at a reasonable level and attaining good ductility whereas PDA above $800{ }^{\circ} \mathrm{C}$ led to grain coarsening and a consequent decrease in strength. Annealing within the appropriate temperature range is the best procedure for preventing grain coarsening and achieving high strength and good ductility. Thus, PDA at $800{ }^{\circ} \mathrm{C}$ for 60 min leads to good mechanical properties with a UTS and elongation to failure of $>1 \mathrm{GPa}$ and $\sim 40 \%$, respectively.

4- There is good agreement between the measured experimental yield stresses and the calculated values for the $\mathrm{CoCrFeNiMnTi} i_{0.1}$ HEA after HPT processing and after PDA at temperatures from 600 to $900{ }^{\circ} \mathrm{C}$. The calculations show that the additional strengthening comes primarily from the grain boundaries through the Hall-Petch relationship.

5- The results demonstrate that an addition of only 2 at.\% $\mathrm{Ti}$ improves the mechanical properties and thermal stability of the CoCrFeNiMn HEA by stabilizing precipitates up to 800 ${ }^{\circ} \mathrm{C}$ where these precipitates are very effective in restricting grain coarsening.

\section{Acknowledgments}

This work was supported by the National Elites Foundation of Islamic Republic of Iran and in part by the European Research Council under Grant Agreement No. 267464-SPDMETALS (TGL). A part of this work was carried out within the statutory funds of the Faculty of Materials Science and Engineering of Warsaw University of Technology (MA and ML). 


\section{References}

1. B. Cantor, I.T.H. Chang, P. Knight, A.J.B. Vincent, Microstructural development in equiatomic multicomponent alloys, Mater. Sci. Eng. A 375-377 (2004) 213-218.

2. F. Otto, A. Dlouhý, Ch. Somsen, H. Bei, G. Eggeler, E.P. George, The influences of temperature and microstructure on the tensile properties of a $\mathrm{CoCrFeMnNi}$ high-entropy alloy, Acta Mater. 61 (2013) 5743-5755.

3. F. Otto, Y. Yang, H. Bei, E.P. George, Relative effects of enthalpy and entropy on the phase stability of equiatomic high-entropy alloys, Acta Mater. 61 (2013) 2628-2638.

4. B. Gludovatz, A. Hohenwarter, D. Catoor, E.H. Chang, E.P. George, R.O. Ritchie, A fracture-resistant high-entropy alloy for cryogenic applications, Science 345 (2014) 11531158.

5. F. Otto, N.L. Hanold, E.P. George, Microstructural evolution after thermomechanical processing in an equiatomic, single-phase $\mathrm{CoCrFeMnNi}$ high-entropy alloy with special focus on twin boundaries, Intermetallics 54 (2014) 39-48.

6. R. Valiev, Nanomaterial advantage, Nature 419 (2002) 887-889.

7. A.P. Zhilyaev, G.V. Nurislamova, B.-K. Kim, M.D. Baró, J.A. Szpunar, T.G. Langdon, Experimental parameters influencing grain refinement and microstructural evolution during high-pressure torsion, Acta Mater. 51 (2003) 753-765.

8. A.P. Zhilyaev, T.G. Langdon, Using high-pressure torsion for metal processing: Fundamentals and applications, Prog. Mater. Sci. 53 (2008) 893-979.

9. B. Schuh, F. Mendez-Martin, B. Völker, E.P. George, H. Clemens, R. Pippan, A. Hohenwarter, Mechanical properties, microstructure and thermal stability of a nanocrystalline CoCrFeMnNi high-entropy alloy after severe plastic deformation, Acta Mater. 96 (2015) 258-268.

10. H. Shahmir, J.Y. He, Z.P. Lu, M. Kawasaki, T.G. Langdon, Effect of annealing on 
mechanical properties of a nanocrystalline CoCrFeNiMn high-entropy alloy processed by high-pressure torsion, Mater. Sci. Eng. A676 (2016) 294-303.

11. R.Z. Valiev, R.K. Islamgaliev, I.V. Alexandrov, Bulk nanostructured materials from severe plastic deformation, Prog. Mater. Sci. 45(2000) 103-189.

12. R.Z. Valiev, A.V. Sergueeva, A.K. Mukherjee, The effect of annealing on tensile deformation behaviour of nanostructured SPD titanium, Scr. Mater. 49 (2003) 669-674.

13. C.C. Koch, Optimization of strength and ductility in nanocrystalline and ultrafine grained metals, Scr. Mater. 49 (2003) 657-662.

14. M.H. Tsai, J.W. Yeh, High-entropy alloys: A critical review, Mater. Res. Lett. 2 (2014) 107-123.

15. R.B. Figueiredo, P.R. Cetlin, T.G. Langdon, Using finite element modelling to examine the flow processes in quasi-constrained high-pressure torsion, Mater. Sci. Eng. A 528 (2011) 8198-8204.

16. G.K. Williamson, W.H. Hall, X-ray line broadening from filed aluminium and wolfram, Acta Metall. 1 (1953) 22-31.

17. Z. Zhang, F. Zhou, E. J. Lavernia, On the analysis of grain size in bulk nanocrystalline materials via X-ray, Metall Mater Trans. A, 34A (2003) 1349-1355.

18. J. Wang J, Z. Horita, M. Furukawa, M. Nemoto, N.K. Tsenev, R.Z. Valiev, Y. Ma, T.G. Langdon, An investigation of ductility and microstructural evolution in an Al-3\% Mg alloy with submicron grain size, J. Mater. Res. 8 (1993) 2810-2818.

19. D-H. Lee, I-C. Choi, M-Y. Seok, J. He, Z. Lu, J-Y. Suh, M. Kawasaki, T.G. Langdon, J-I. Jang, Nanomechanical behavior and structural stability of a nanocrystalline CoCrFeNiMn high-entropy alloy processed by high-pressure torsion, J. Mater. Res. 30 (2015) 2804-2815.

20. P.F. Yu, H. Cheng, L.J. Zhang, H. Zhang, Q. Jing, M.Z. Ma, P.K. Liaw, G. Li, R.P. Liu, Effects of high pressure torsion on microstructures and properties of an $\mathrm{Al}_{0.1} \mathrm{CoCrFeNi}$ high-entropy alloy, Mater. Sci. Eng. A 655 (2016) 283-291. 
21. M.H. Tsai, H. Yuan, G. Cheng, W. Xu, W.W. Jian, M.H. Chuang, C.C. Juan, A.C. Yeh, S.J. Lin, Y. Zhu, Significant hardening due to the formation of a sigma phase matrix in a high entropy alloy, Intermetallics 33 (2013) 81-86.

22. F. Zhang, C. Zhang, S.L. Chen, J. Zhu, W.S. Cao, U.R. Kattner, An understanding of high entropy alloys from phase diagram calculations, CALPHAD 45 (2014) 1-10.

23. F. Otto, A. Dlouhý, K.G. Pradeep, M. Kuběnová, D. Raabe, G. Eggeler, E.P. George, Decomposition of the single-phase high-entropy alloy $\mathrm{CrMnFeCoNi}$ after prolonged anneals at intermediate temperatures, Acta Mater. 112 (2016) 40-52.

24. E.J. Pickering, R. Muñoz-Moreno, H.J. Stone, N.G. Jones, Precipitation in the equiatomic high-entropy alloy CrMnFeCoNi, Scr. Mater. 113 (2016) 106-109.

25. R.F. Decker, Alloy design using second phases, Metall. Trans. 4 (1973) 2495-2518.

26. N.D. Stepanov, D.G. Shaysultanov, M.S. Ozerov, S.V. Zherebtsov, G.A. Salishchev, Second phase formation in the CoCrFeNiMn high entropy alloy after recrystallization annealing, Mater. Lett. 185 (2016) 1-4.

27. H. Shahmir, T. Mousavi, J. He, Z. Lu, M. Kawasaki, T.G. Langdon, Microstructure and properties of a CoCrFeNiMn high-entropy alloy processed by equal-channel angular pressing, Mare. Sci. Eng. A 705 (2017) 411-419.

28. R.Z. Valiev, I.V. Alexandrov, Y.T. Zhu, T.C. Lowe, Paradox of strength and ductility in metals processed by severe plastic deformation, J. Mater. Res. 17 (2002) 5-8.

29. P. Kumar, M. Kawasaki, T.G. Langdon, Review: Overcoming the paradox of strength and ductility in ultrafine-grained materials at low temperatures, J. Mater. Sci. 51 (2016) 7-18.

30. K.Y. Tsai, M.H. Tsai, J.W. Yeh, Sluggish diffusion in $\mathrm{Co}-\mathrm{Cr}-\mathrm{Fe}-\mathrm{Mn}-\mathrm{Ni}$ high-entropy alloys, Acta Mater. 61 (2013) 4887-4897.

31. W.H. Liu, Y. Wu, J.Y. He, T.G. Nieh, Z.P. Lu, Grain growth and the Hall-Petch relationship in a high-entropy FeCrNiCoMn alloy, Scr Mater 68 (2013) 526-529. 
32. P.P. Bhattacharjee, G.D. Sathiaraj, M. Zaid, J.R. Gatti, C. Lee, C.-W. Tsai, J.-W. Yeh, Microstructure and texture evolution during annealing of equiatomic $\mathrm{CoCrFeMnNi}$ highentropy alloy, J. Alloy. Compd. 587 (2014) 544-552.

33. G.D. Sathiaraj, P.P. Bhattacharjee, Analysis of microstructure and microtexture during grain growth in low stacking fault energy equiatomic $\mathrm{CoCrFeMnNi}$ high entropy and $\mathrm{Ni}$ 60 wt.\%Co alloys, J. Alloy. Compd. 637 (2015) 267-276.

34. J.Y. He, W.H. Liu, H. Wang, Y. Wu, X.J. Liu, T.G. Nieh, Z.P. Lu, Effects of Al addition on structural evolution and tensile properties of the FeCoNiCrMn high-entropy alloy system, Acta Mater 62 (2014) 105-113.

35. D.A. Hughes, N. Hansen, Microstructure and strength of nickel at large strains, Acta Mater. 48 (2000) 2985-3004.

36. E.O. Hall, The deformation and ageing of mild steel. III Discussion of results, Proc. Phys. Soc. B 64 (1951) 747-753.

37. N.J. Petch, The cleavage strength of polycrystals, J. Iron Steel Inst. 174 (1953) 25-28.

38. J.E. Bailey, P.B. Hirsch, The dislocation density, flow stress, and stored energy in coldworked polycrystalline silver, Phil. Mag. 5 (1960) 485-497.

39. J.Y. He, C. Zhu, D.Q. Zhou, W.H. Liu, T.G. Nieh, Z.P. Lu, Steady state flow of the FeCoNiCrMn high entropy alloy at elevated temperatures, Intermetal. 55 (2014) 9-14.

40. G. Laplanche, P. Gadaud, O. Horst, F. Otto, G. Eggeler, E.P. George, Temperature dependencies of the elastic moduli and thermal expansion coefficient of an equiatomic, single-phase CoCrFeMnNi high-entropy alloy, J. Alloys Compd. 623 (2015) 348-353.

41. E. Orowan, in: M. Cohen (ed.), Dislocations in Metals, AIME, New York, 1954, p. 69. 


\section{Table captions:}

Table 1. Volume fraction of precipitates $\left(V_{p}\right)$, grain size $(d)$, microhardness, YS, UTS and elongation $(\delta)$ of the CoCrFeNiMnTi0.1 and CoCrFeNiMn alloy [10] in the initial condition and before and after PDA at $500-900{ }^{\circ} \mathrm{C}$ for $60 \mathrm{~min}$.

Table 2. The contributions of intrinsic strength $\left(\sigma_{0}\right)$, solid solution effect of $\mathrm{Ti}\left(\sigma_{\mathrm{S}(\mathrm{Ti})}\right)$, grain boundary strengthening $\left(\sigma_{g b}\right)$, dislocation strengthening $\left(\sigma_{\rho}\right)$ and precipitation strengthening $\left(\sigma_{P}\right)$ for each condition and comparisons between the calculated and experimentally obtained yield stress of the HPT-processed sample and samples after PDA at $600-900{ }^{\circ} \mathrm{C}$ for 60 min (all values in $\mathrm{MPa})$. 


\section{Figure captions:}

Fig. 1 Optical micrographs of the microstructure of the $\mathrm{CoCrFeNiMnTi}_{0.1}$ alloy after homogenizing: the arrows show Mn-Ti oxides.

Fig. 2 Values of the Vickers microhardness measured across disks processed from $1 / 4$ to 10 turns at a rotation speed of $1 \mathrm{rpm}$ : the lower dashed line shows the homogenized initial condition.

Fig. 3 X-ray patterns of the homogenized $(N=0)$ condition and near the edge of the disks processed from 1 to 5 turns at a rotation speed of $1 \mathrm{rpm}$.

Fig. 4 (a) TEM image and corresponding SAED pattern and (b) TEM image with higher magnification after 5 turns of HPT processing.

Fig. 5 Dependence of Vickers hardness of the homogenized and HPT-processed samples on the annealing temperature; the annealing time is $60 \mathrm{~min}$.

Fig. 6 X-ray patterns near the edges of disks after HPT processing followed by PDA at 400-900 ${ }^{\circ} \mathrm{C}$ for $60 \mathrm{~min}$.

Fig. 7 (a) TEM image and (b) corresponding SAED pattern of a sample after 5 turns of HPT processing followed by PDA at $600{ }^{\circ} \mathrm{C}$ for $60 \mathrm{~min}$; equiaxed grains with a mean grain size of $\sim 100 \mathrm{~nm}$ in (a) and in (b) the SAED pattern clearly shows sharp spots related to precipitates; (c) Dark field image of the microstructure showing dispersion of $b c c$ precipitates with an average size of $\sim 100 \mathrm{~nm}$ in the matrix; (d) TEM image of the microstructure with higher magnification; the arrows show nano precipitates $(\sim 25 \mathrm{~nm})$ dispersed in the grains and the circles show precipitates formed at the grain boundaries and triple junctions.

Fig. 8 Chemical analyses of the sample after PDA at $600{ }^{\circ} \mathrm{C}$ for $60 \mathrm{~min}$ showing Ni-rich nano precipitates.

Fig. 9 Chemical analyses of the sample after PDA at $600{ }^{\circ} \mathrm{C}$ for 60 min showing Cr-rich phases.

Fig. 10 FESEM observation of unetched samples after PDA for $60 \mathrm{~min}$ at (a) 600, (b) 700 and 
(c) $800{ }^{\circ} \mathrm{C}$; arrows show precipitated phase in the matrix; (d) OM observation of etched sample after PDA at $900{ }^{\circ} \mathrm{C}$.

Fig. 11 FESEM observation of etched samples after PDA for 60 min at (a) 700, (b) 800 and (c) $850^{\circ} \mathrm{C}$; arrows show precipitated phase in the matrix and chemical analyses of precipitated phase and the matrix reported in at.\% after EDS analysis.

Fig. 12 Engineering stress- engineering strain curves at an initial strain rate of $1.0 \times 10^{-3} \mathrm{~s}^{-1}$ in the homogenized and HPT-processed conditions and after PDA at $700-850{ }^{\circ} \mathrm{C}$ for $60 \mathrm{~min}$. 


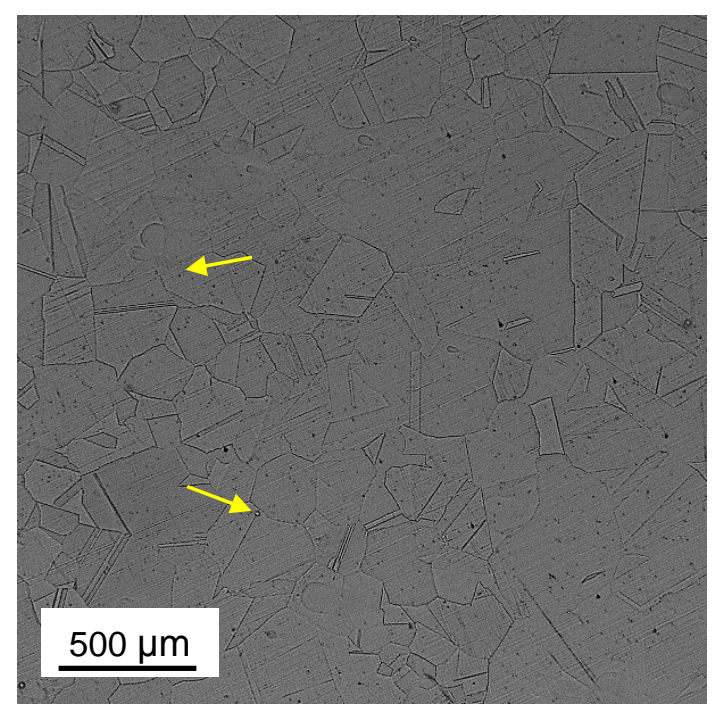

Fig. 1 Optical micrograph of the microstructure of the CoCrFeNiMnTi0.1 alloy after homogenizing: the arrows show Mn-Ti oxides. 


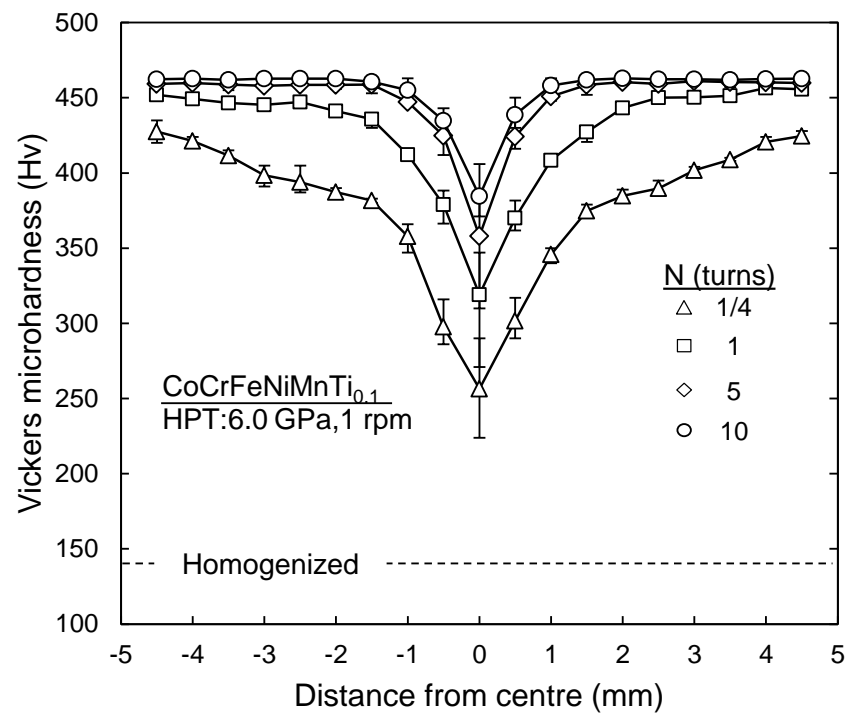

Fig. 2 Values of the Vickers microhardness measured across disks processed from 1/4 to 10 turns at a rotation speed of $1 \mathrm{rpm}$ : the lower dashed line shows the homogenized initial condition. 


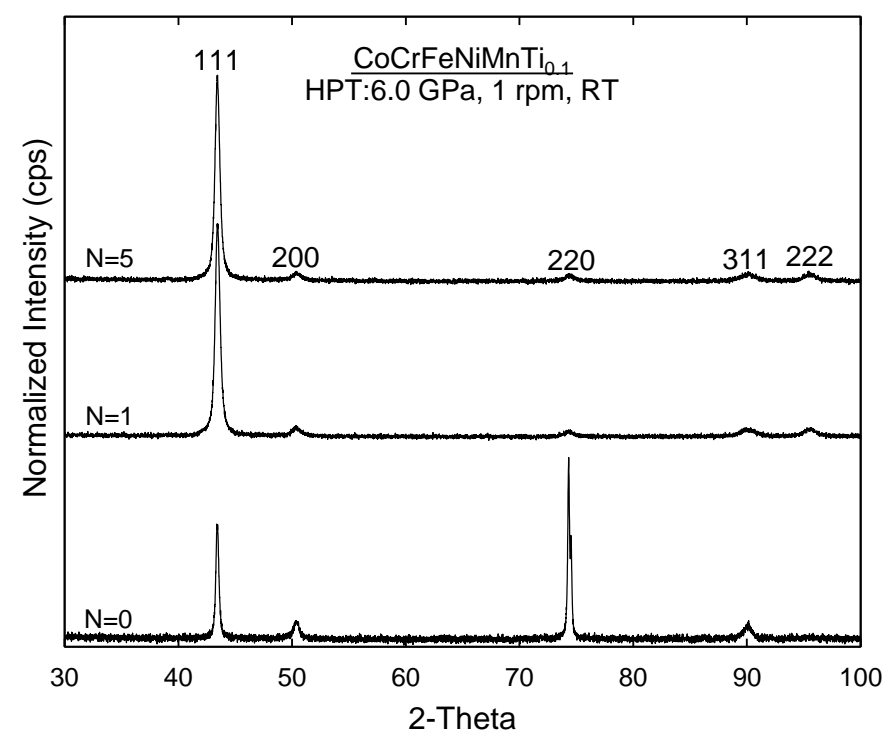

Fig. $3 \mathrm{X}$-ray patterns of the homogenized $(N=0)$ condition and near the edge of the disks processed from 1 to 5 turns at a rotation speed of $1 \mathrm{rpm}$. 

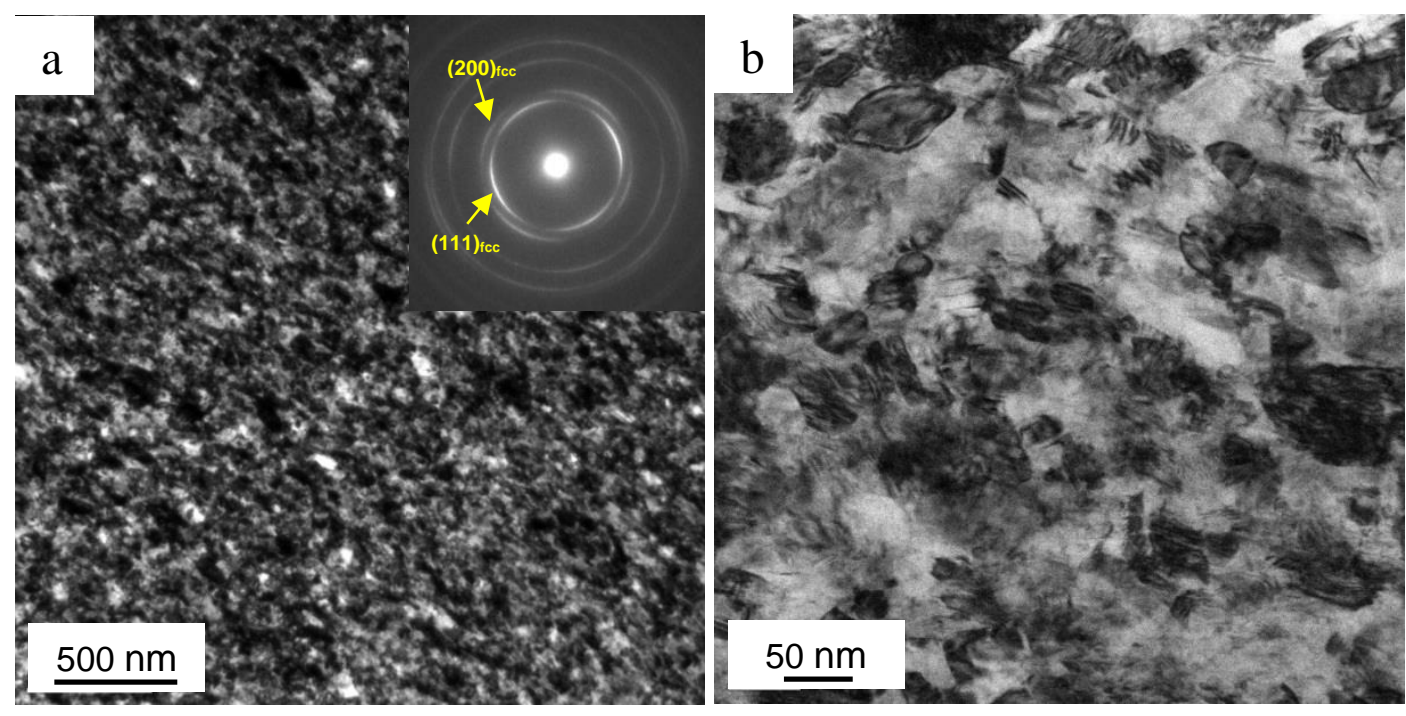

Fig. 4 (a) TEM image and corresponding SAED pattern and (b) TEM image with higher magnification after 5 turns of HPT processing. 


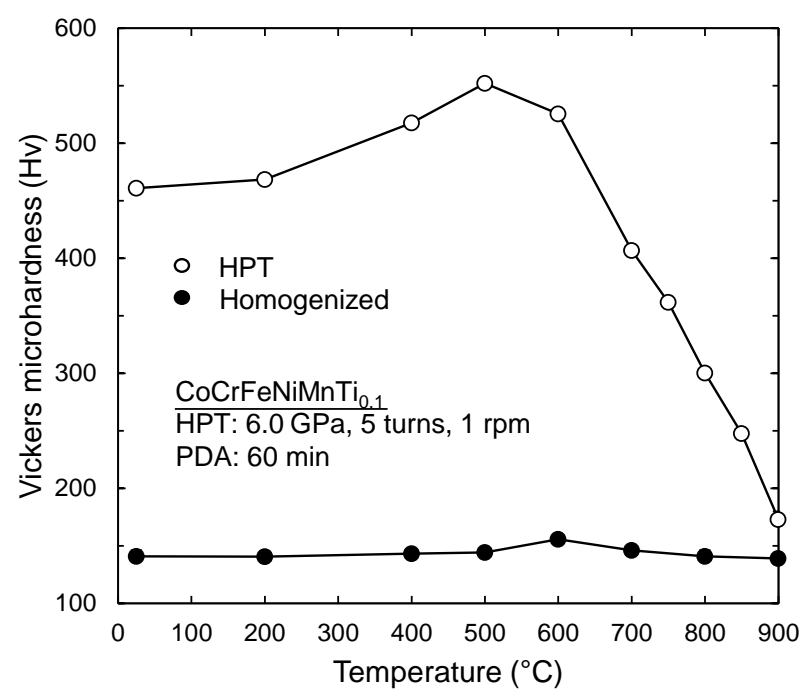

Fig. 5 Dependence of Vickers hardness of the homogenized and HPT-processed samples on the annealing temperature; the annealing time is $60 \mathrm{~min}$. 


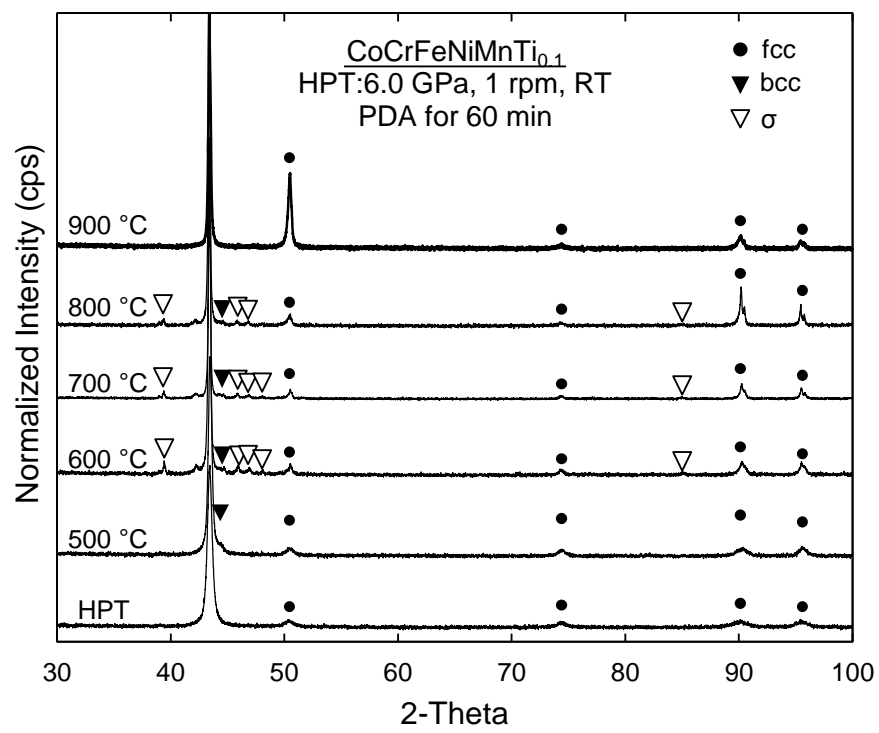

Fig. 6 X-ray patterns near the edge of disks after HPT processing followed by PDA at $400-900{ }^{\circ} \mathrm{C}$ for $60 \mathrm{~min}$. 

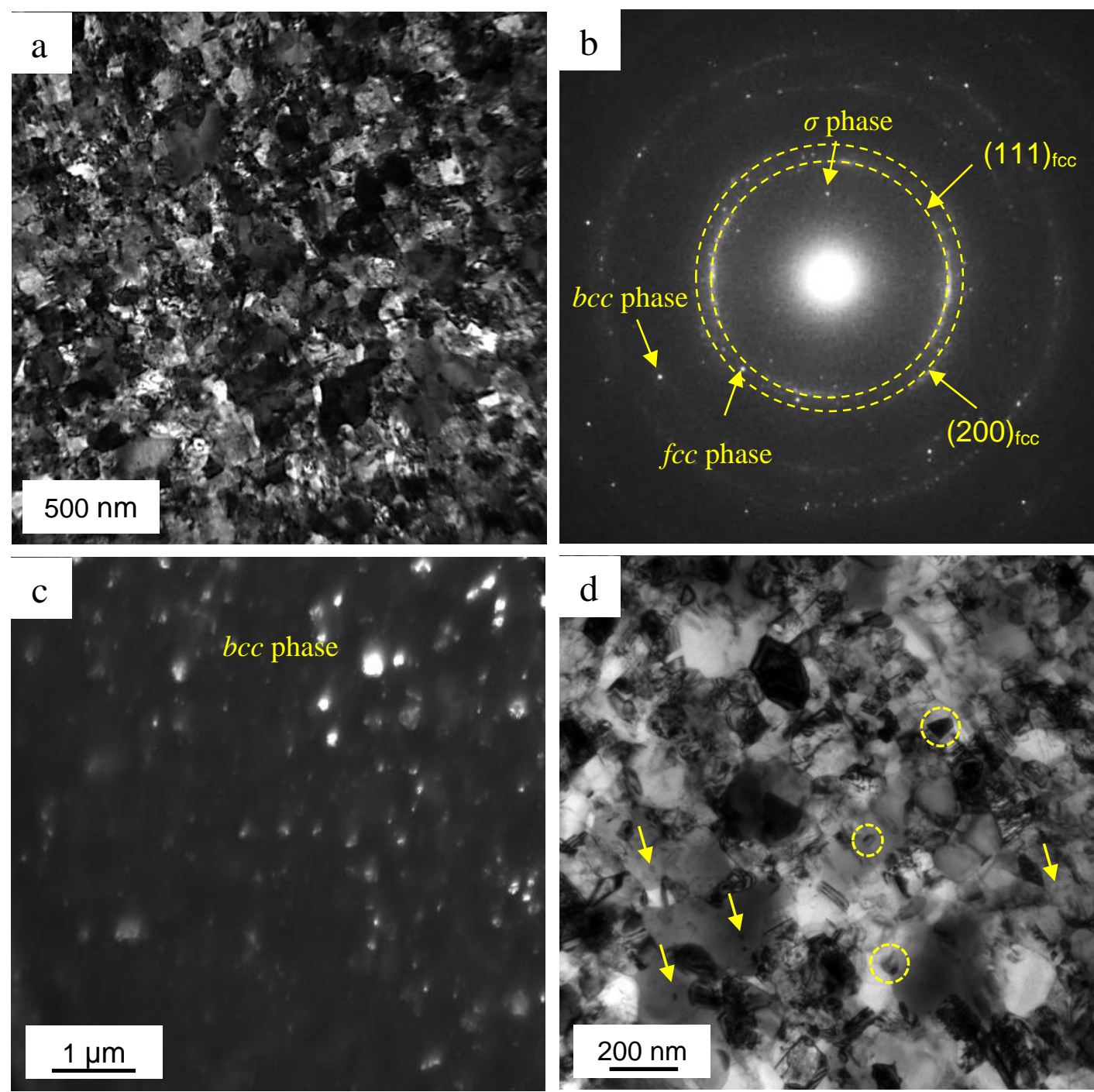

Fig. 7 (a) TEM image and (b) corresponding SAED pattern of a sample after 5 turns of HPT processing followed by PDA at $600{ }^{\circ} \mathrm{C}$ for 60 min; equiaxed grains with a mean grain size of $\sim 100$ $\mathrm{nm}$ in (a) and in (b) the SAED pattern clearly shows sharp spots related to precipitates; (c) Dark filed image of the microstructure showing dispersion of $b c c$ precipitates with an average size of $100 \mathrm{~nm}$ in the matrix; (d) TEM image of the microstructure with higher magnification; the arrows show nano precipitates $(25 \mathrm{~nm})$ dispersed in grains and the circles show precipitates formed at the garin boundaries and triple junctions. 

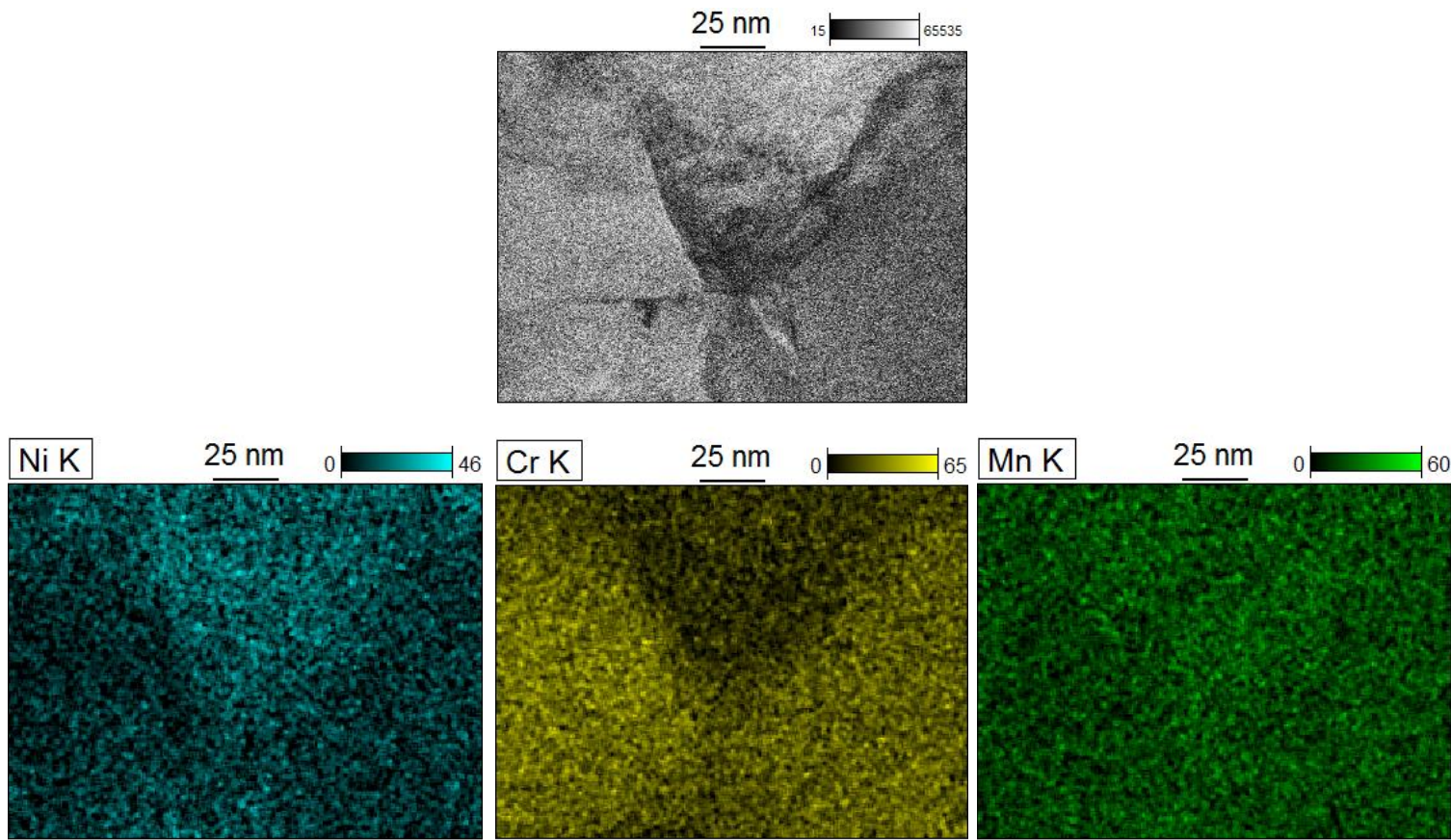

Fig. 8 Chemical analyses of the sample after PDA at $600{ }^{\circ} \mathrm{C}$ for $60 \mathrm{~min}$ showing Ni-rich nano precipitates. 

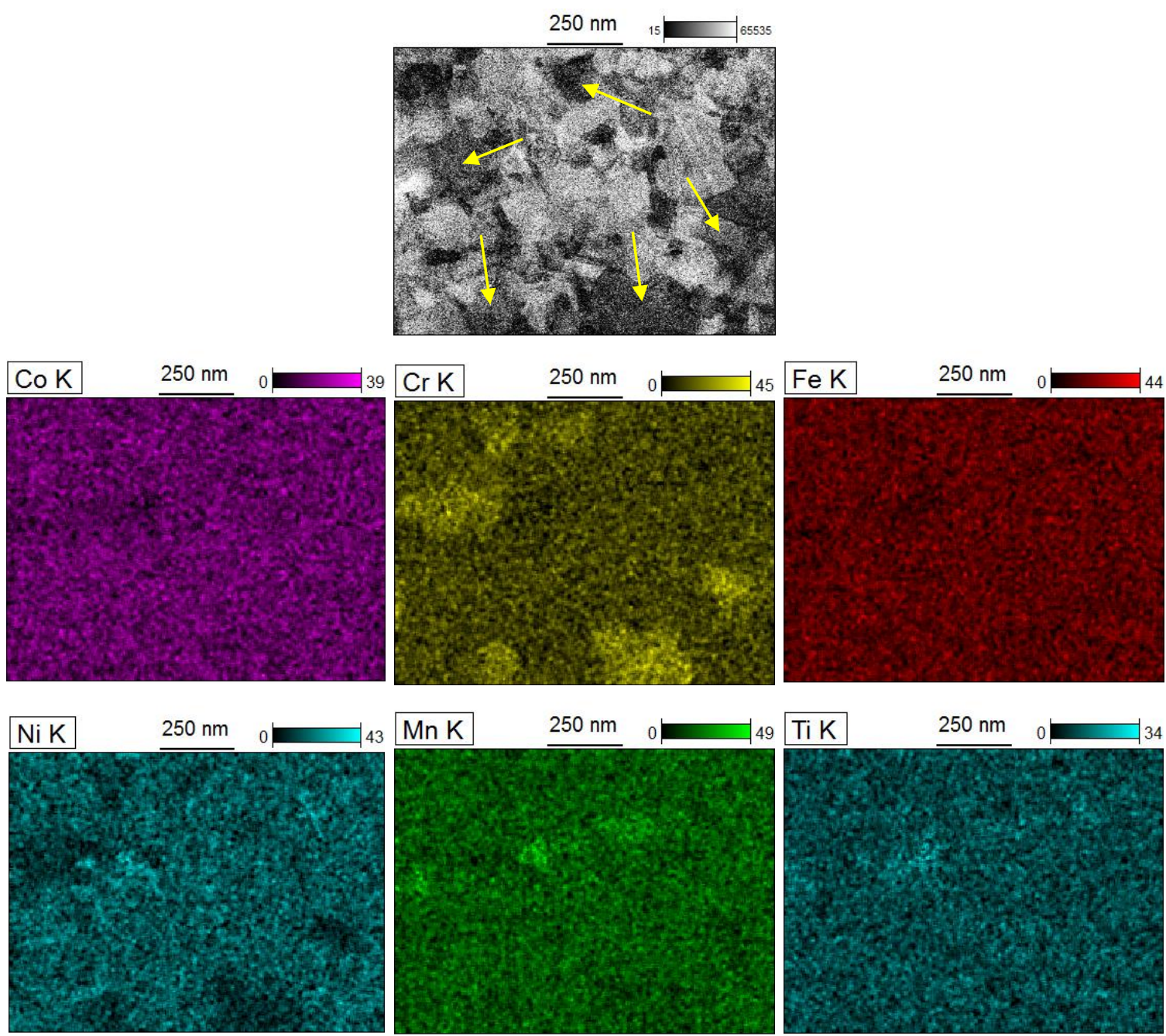

Fig. 9 Chemical analyses of the sample after PDA at $600{ }^{\circ} \mathrm{C}$ for 60 min showing $\mathrm{Cr}$-rich phases. 


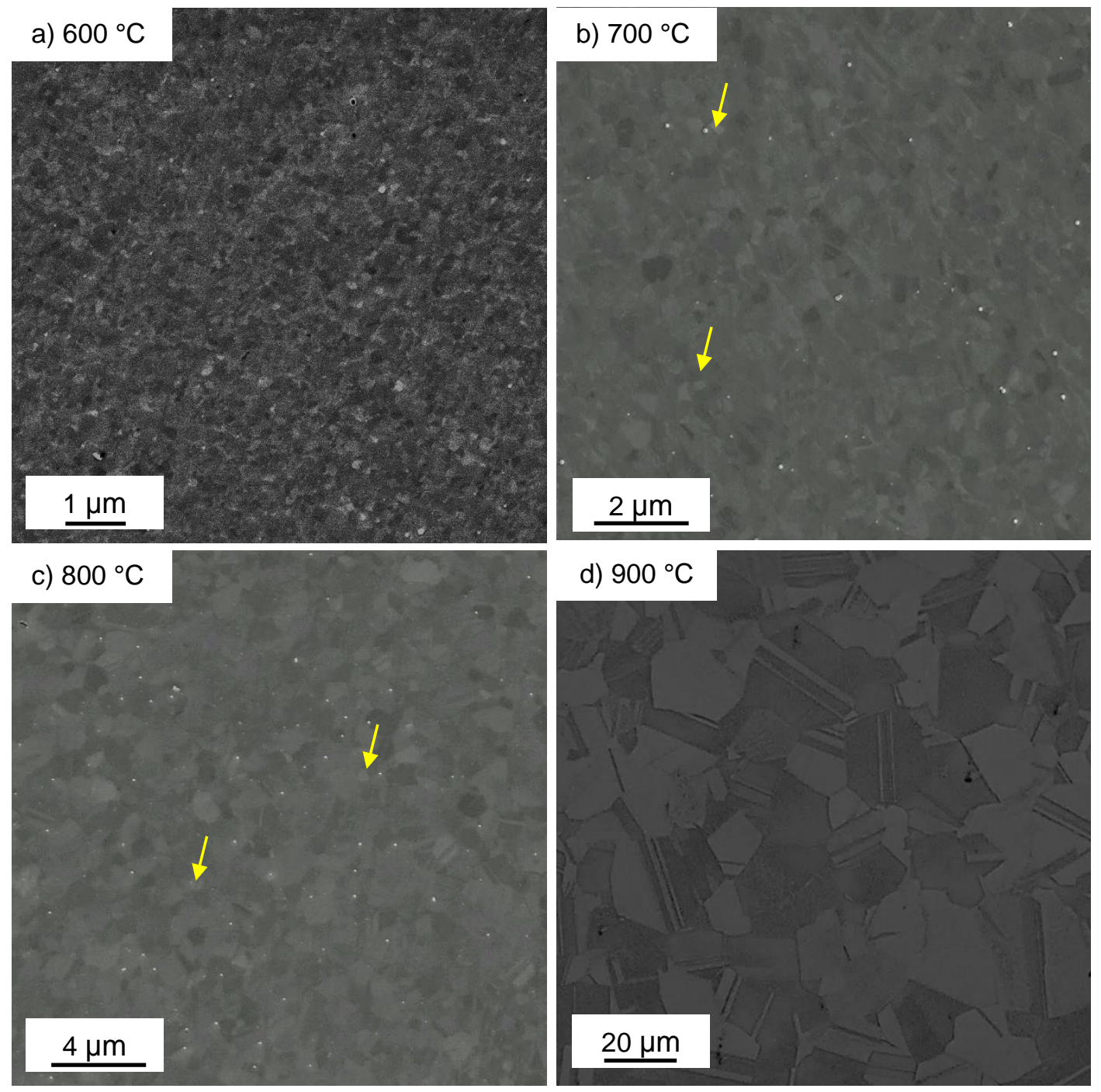

Fig. 10 FESEM observation of unetched samples after PDA for 60 min at (a) 600, (b) 700 and

(c) $800{ }^{\circ} \mathrm{C}$; arrows show precipitated phase in the matrix; (d) OM observation of eatched sample after PDA at $900{ }^{\circ} \mathrm{C}$. 


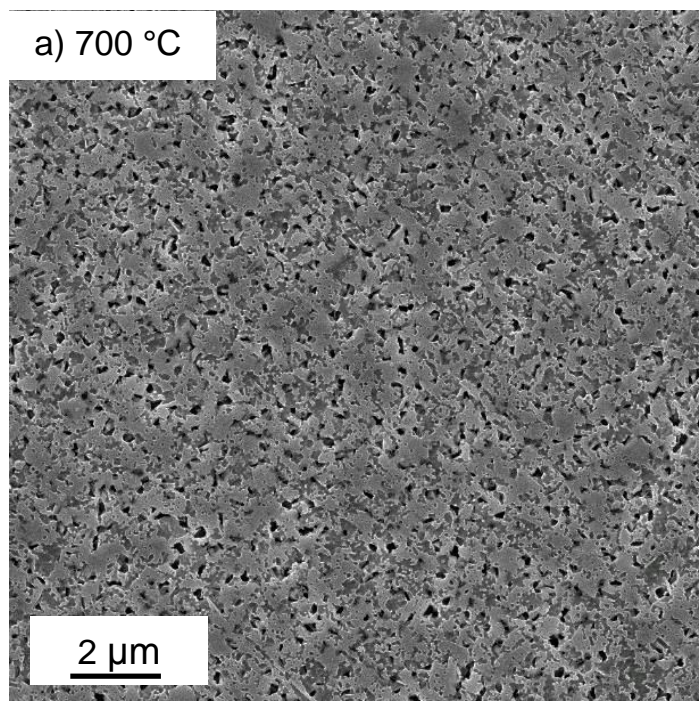

b) $800^{\circ} \mathrm{C}$

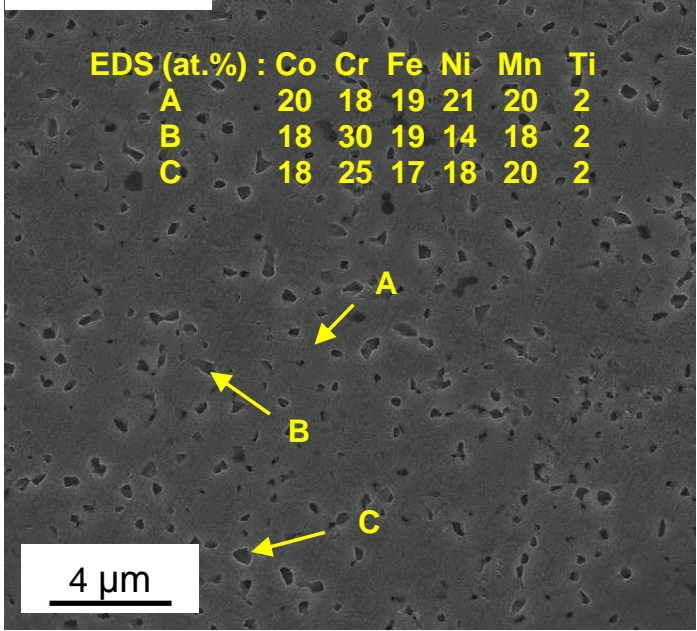

c) $850^{\circ} \mathrm{C}$

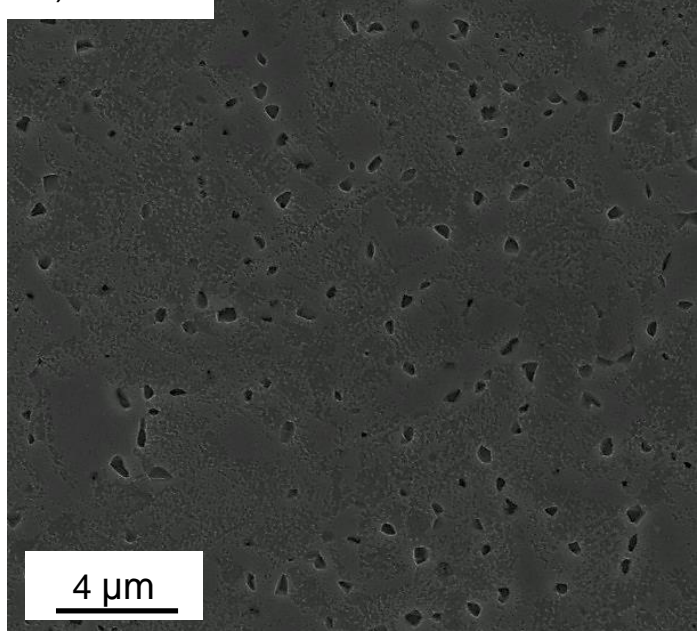

Fig. 11 FESEM observation of etched samples after PDA for 60 min at (a) 700, (b) 800 and

(c) $850{ }^{\circ} \mathrm{C}$; arrows show precipitated phase in the matrix and chemical analyses of precipitated phase and the matrix reported in at.\% after EDS analysis. 


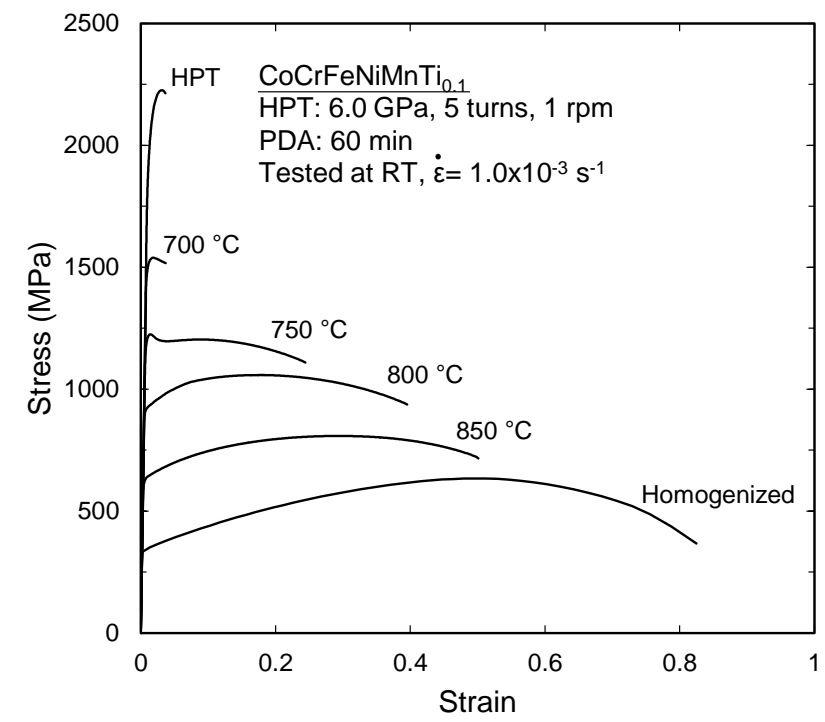

Fig. 12 Engineering stress- engineering strain curves at an initial strain rate of $1.0 \times 10^{-3} \mathrm{~s}^{-1}$ in the homogenized and HPT-processed conditions and after PDA at $700-850{ }^{\circ} \mathrm{C}$ for $60 \mathrm{~min}$. 
Table 1. Volume fraction of precipitates $\left(V_{p}\right)$, grain size $(d)$, microhardness, YS, UTS and elongation $(\delta)$ of the $\mathrm{CoCrFeNiMnTi} i_{0.1}$ and $\mathrm{CoCrFeNiMn}$ alloy [10] in the initial condition and before and after PDA at $500-900{ }^{\circ} \mathrm{C}$ for $60 \mathrm{~min}$.

\begin{tabular}{|c|c|c|c|c|c|c|c|c|}
\hline Composition & $\begin{array}{c}\text { Annealing } \\
\text { Temperature }\left({ }^{\circ} \mathrm{C}\right)\end{array}$ & $d$ & $\begin{array}{l}V_{p} \\
(\%)\end{array}$ & $\mathrm{Hv}$ & $\begin{array}{c}\mathrm{YS} \\
(\mathrm{MPa})\end{array}$ & $\begin{array}{l}\text { UTS } \\
(\mathrm{MPa})\end{array}$ & $\begin{array}{c}\delta \\
(\%)\end{array}$ & Reference \\
\hline \multirow{9}{*}{$\mathrm{CoCrFeNiMnTi} i_{0.1}$} & Initial condition & $200 \mu \mathrm{m}$ & 0 & 140 & 350 & 630 & 85 & \multirow{9}{*}{$\begin{array}{l}\text { Present } \\
\text { research }\end{array}$} \\
\hline & HPT & $40 \mathrm{~nm}$ & 0 & 460 & 1950 & 2220 & 3 & \\
\hline & $500^{*}$ & $80 \mathrm{~nm}$ & $\sim 15$ & 550 & - & - & - & \\
\hline & $600^{*}$ & $100 \mathrm{~nm}$ & $\sim 18$ & 525 & - & - & - & \\
\hline & 700 & $400 \mathrm{~nm}$ & $\sim 15$ & 405 & 1490 & 1540 & 4 & \\
\hline & 750 & $900 \mathrm{~nm}$ & $\sim 12$ & 360 & 1190 & 1220 & 25 & \\
\hline & 800 & $1.1 \mu \mathrm{m}$ & $\sim 8$ & 300 & 910 & 1060 & 40 & \\
\hline & 850 & $2 \mu \mathrm{m}$ & $\sim 5$ & 250 & 620 & 810 & 50 & \\
\hline & 900 & $14 \mu \mathrm{m}$ & 0 & 150 & - & - & - & \\
\hline \multirow{7}{*}{ CoCrFeNiMn } & Initial condition & $200 \mu \mathrm{m}$ & 0 & 120 & 300 & 530 & 85 & \multirow{7}{*}{$\begin{array}{l}\text { Shahmir } \\
\text { et al. [10] }\end{array}$} \\
\hline & HPT & $10 \mathrm{~nm}$ & 0 & 450 & 1400 & 1740 & 4 & \\
\hline & 500 & $60 \mathrm{~nm}$ & $\sim 17$ & 520 & 930 & 1250 & 5 & \\
\hline & 600 & $90 \mathrm{~nm}$ & $\sim 10$ & 455 & 1010 & 1060 & 2 & \\
\hline & 700 & $400 \mathrm{~nm}$ & $\sim 7$ & 355 & 950 & 1030 & 21 & \\
\hline & 800 & $4 \mu \mathrm{m}$ & $<5$ & 220 & 530 & 680 & 80 & \\
\hline & 900 & $17 \mu \mathrm{m}$ & 0 & 140 & 370 & 600 & 90 & \\
\hline
\end{tabular}

* Samples were very brittle and failed before yield point. 
Table 2. The contributions of intrinsic strength $\left(\sigma_{0}\right)$, solid solution effect of $\mathrm{Ti}\left(\sigma_{S(T i)}\right)$, grain boundary strengthening $\left(\sigma_{g b}\right)$, dislocation strengthening $\left(\sigma_{\rho}\right)$ and precipitation strengthening $\left(\sigma_{P}\right)$ for each condition and comparison between the calculated and experimentally obtained yield stress of HPT-processed sample and samples after PDA at $600-900{ }^{\circ} \mathrm{C}$ for $60 \mathrm{~min}$ (all values in $\mathrm{MPa})$.

\begin{tabular}{ccccccccccc}
\hline $\begin{array}{c}\text { Annealing } \\
\text { Temp. }\left({ }^{\circ} \mathrm{C}\right)\end{array}$ & $\sigma_{0}$ & $\sigma_{S(\mathrm{Ti})}$ & $\sigma_{g b}$ & $\sigma_{\rho}$ & $\sigma_{P I(\text { orawan })}$ & $\sigma_{0.2 m}$ & $f_{\mathrm{m}} \times \sigma_{0.2 m}$ & $f_{\mathrm{P} 2} \times \sigma_{\mathrm{P} 2}$ & $\sigma_{0.2 c a l}$ & $\sigma_{0.2 \exp }$ \\
\hline- & 165 & 12 & 1130 & 657 & 0 & 1964 & $1 \times 1964$ & 0 & 1964 & 1960 \\
600 & 165 & 12 & 714 & 156 & 1264 & 2311 & $0.72 \times 2311$ & $0.18 \times 3200$ & 2239 & - \\
700 & 165 & 12 & 357 & 85 & 505 & 1124 & $0.75 \times 1124$ & $0.15 \times 3200$ & 1323 & 1500 \\
800 & 165 & 12 & 215 & 49 & 168 & 609 & $0.92 \times 609$ & $0.08 \times 3200$ & 816 & 910 \\
\hline
\end{tabular}

